\title{
Imagens assírias: entre narrativa e arte
}

\section{Assyrian images: between narrative and art}

\section{Imágenes asirias: entre narrativa y arte}

\author{
Katia Maria Paim Pozzer* \\ Submetido em: 26-6-2021 \\ Aceito em: 24-8-2021
}

* Universidade Federal do Rio Grande do Sul Pós-doutora em História Antiga

E-mail:pozzerk@gmail.com

\begin{abstract}
RESUMO
No mundo mesopotâmico, o relevo sobre pedra foi uma das mais importantes manifestações artísticas. A imponente quantidade de cenas e a sua própria continuidade indicam uma função amplamente documental. A prática cultural de criação destes relevos monumentais está associada ao momento político de construção de grandes impérios. Neste artigo examinamos o relevo do banquete de Assurbanipal e Aššur-šarrat a partir da perspectiva da história da arte e dos fundamentos da iconologia.

Palavras-chave: História; narrativa; arte assíria; Assurbanipal.
\end{abstract}

\begin{abstract}
In the Mesopotamian world, stone relief was one of the most important artistic manifestations. The imposing amount of scenes and its own continuity indicate a largely documentary function. The cultural practice of creating these monumental reliefs is associated with the political moment of making great empires. In this article, we examine the relief of the banquet of Assurbanipal and Ašsur-šarrat since the perspective of art history and the foundations of iconology.

Keywords: History; narrative; Assyrian art; Assurbanipal.

\section{RESUMEN}

En el mundo mesopotámico, el relieve en piedra fue una de las manifestaciones artísticas más importantes. La imponente cantidad de escenas y su propia continuidad indican una función ampliamente documental. La práctica cultural de crear estos relieves monumentales está asociada con el momento político de la construcción de grandes imperios. En este artículo examinamos el relieve del banquete de Assurbanipal y Aššr-šarrat desde la perspectiva de la historia del arte y los fundamentos de la iconología.

Palabras clave: Historia; narrativa; arte asirio; Assurbanipal.
\end{abstract}

Os relevos assírios constituem um dos mais ricos conjuntos iconográficos da arte mesopotâmica. Ao longo de mais de dois séculos os monarcas assírios desenvolveram a prática cultural de criação de relevos monumentais, que recobriam as paredes internas dos palácios, contendo uma narrativa histórica idealizada. Esses relevos eram confeccionados em alabastro, uma pedra maleável, repartida em duas ou mais partes, recobrindo as paredes dos palácios, podendo ultrapassar 2 metros de altura. As evidências materiais deste tipo de relevo datam dos reinados de Assurnazirpal II (883-859 AEC); Salmanassar III (853-824 AEC); Teglatphalassar III (745-727 AEC) e Sargão 
II (722-705 AEC), em Nimrûd; Senaqueribe (705-681 AEC) e Assurbanipal (669-627 AEC), em Nínive. A imponente quantidade de cenas e a sua própria continuidade indicam uma função amplamente documental, uma vez que os relevos parietais possuem correspondência com os anais assírios (MOSCATI, 1985, p. 38; FRANKFORT, 1996, p. 157).

A realização destes relevos monumentais estava associada ao momento político de construção de grandes impérios. A maioria das cenas representadas evocavam a guerra e as campanhas militares empreendidas pelos assírios contra seus inimigos. Segundo o historiador Jean-Jacques Glassner (1993, p. 111):

A cette époque, l'imperialisme assyrien, fort de son idéologie universaliste, a assimilé la guerre à une lute contre les forces du mal. Conçue comme une épreuve ordalique, la guerre est devenue un élément constitutif de l'ordre cosmique. Elle sauve la civilisation, le roi étant l'instrument de la justice divine, et le dieu Assur se parant d'une figure guerrière. (...) Le statut d'inimitié et de négativité de l'ennemi fait que les destructions et les ravages prennent un caractère positif. Le roi assyrien est toujours bon et juste, l'ennemi menteur, mauvais et impur. Les historiens assyriens, serviteurs zélés du prince, répercutent cette idéologie officielle. ${ }^{1}$

Para a investigação destas imagens realizamos a análise formal e simbólica de um relevo em particular, conhecido como o "Banquete sob a Videira". Para tal utilizamos a metodologia baseada na obra de Erwin Panofsky, que divide em três momentos o processo de análise visual em iconografia e iconologia: realização da descrição pré-iconográfica, isto é, a enumeração dos motivos artísticos para cada temática; realização da análise iconográfica, ou seja, da identificação de imagens, estórias e alegorias e realização da interpretação iconológica, que é a descoberta e a interpretação dos valores simbólicos nas imagens. A iconografia é o tema e o significado das obras de arte em contraposição a sua forma e iconologia é o estudo de ícones ou do simbolismo na representação visual (PANOFSKY, 2007, p. 47).

\section{Uma imagem artística}

Segundo Barnett (1976, p. 56), o relevo conhecido como "O Banquete sob a Videira é um dos mais memoráveis e enigmáticos da arte do antigo Oriente Próximo" e foi encontrado na sala S, no andar superior, do palácio

\footnotetext{
Nesta época, o imperialismo assírio, convencido de sua ideologia universal, assimila a guerra a uma luta contra as forças do mal. Concebida como uma experiência ordálica, a guerra tornou-se um elemento constitutivo da ordem cósmica. Ela salva a população, o rei sendo o instrumento da justiça divina, e o deus Assur se vestindo de uma figura guerreira. (...) O estatuto de inimizade e de negatividade do inimigo faz com que as destruições e as devastações adquiram um caráter positivo. O rei assírio é sempre bom e justo, o inimigo mentiroso, mau e impuro. (Tradução nossa).
} 
norte em Nínive, durante as escavações arqueológicas realizadas entre 1852 e 1932 (CURTIS; READE, 1975; RUSSEL, 1995, p. 295).

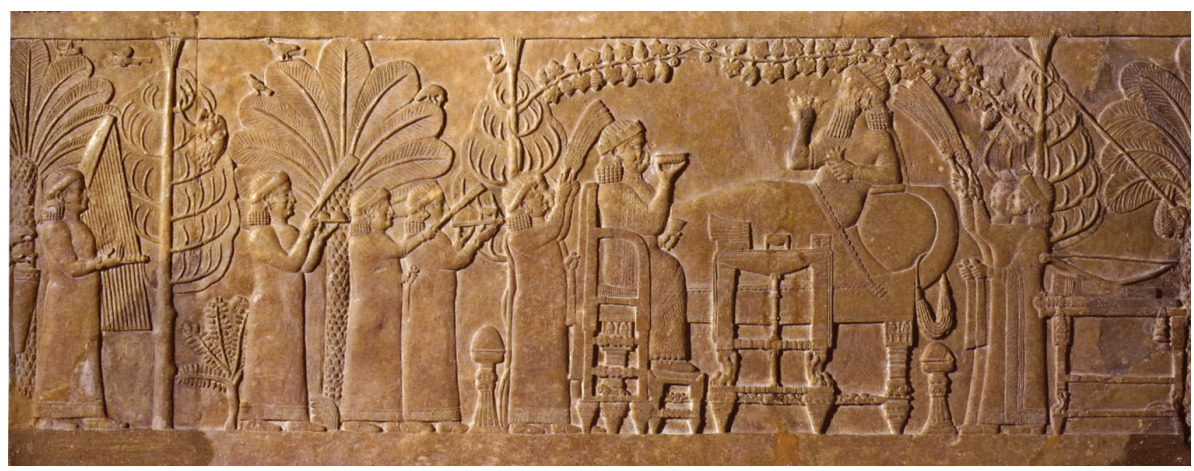

Figura 1: O Banquete sob a Videira.

Alabastro. Iraque, Kouyunjik (Nínive) - Museu Britânico, Londres.

Altura: 1,34 m Largura: 1,53 m.

Reinado de Assurbanipal (668-631 AEC).

(C) The Trustees of the British Museum

https://www.britishmuseum.org/collection/image/237000001

Trata-se de uma narrativa histórica de rara beleza, ambientada em um jardim na propriedade real, e que conta com vários elementos naturalistas na sua composição. Em um jardim de palmeiras e pinos, sob uma videira carregada de frutos, o rei Assurbanipal e sua esposa, a rainha Aššur-šarrat, participam de um banquete cuja composição é bastante atípica, uma vez que o casal real se encontra só, isolado por dois queimadores de perfume e cercado apenas por serviçais. A cena pode ser compreendida como a apoteose da glorificação do poder de Assurbanipal.

No imaginário oriental, tanto antigo quanto contemporâneo, o jardim tem um papel fundamental no urbanismo e na vida cotidiana. Na Mesopotâmia, os jardins surgiram juntamente com as cidades e a necessidade das comunidades de enfrentar a aridez dos desertos e das estepes. Eles desenvolveram uma tecnologia de irrigação que permitiu dar vida aos jardins com árvores frutíferas bem como às árvores ornamentais. A árvore da vida citada em Gênesis 2,8 tornou-se uma imagem simbólica do paraíso. Um exemplo é a imagem abaixo que mostra um fragmento de um relevo assírio de Assurbanipal e em seguida a reconstituição colorizada do mesmo (Figs. 2 e 3). É possível identificar um jardim com canais de irrigação alimentados por um aqueduto (JARDINS D'ORIENT, 2016). 


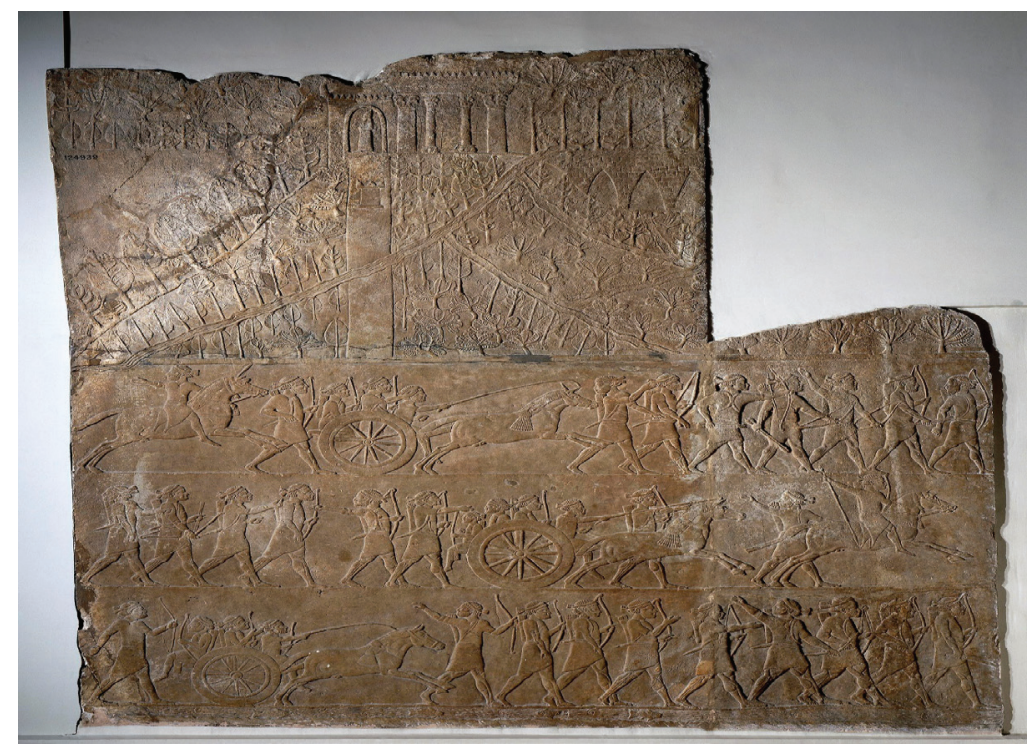

Figura 2: Jardim com aqueduto (fragmento).

Alabastro. Iraque, Kouyunjik (Nínive) - Museu Britânico, Londres.

Altura: 1,32 m Largura: 0,58 m.

(C) The Trustees of the British Museum

https://www.britishmuseum.org/collection/object/W_1856-0909-36

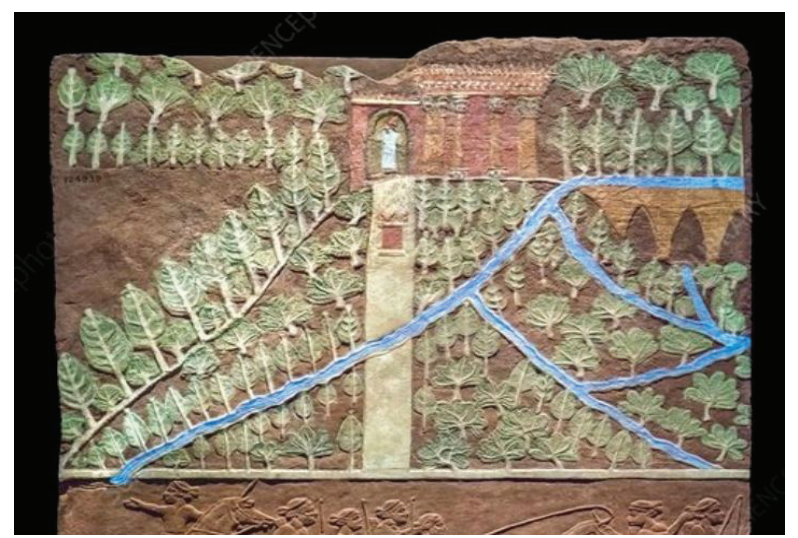

Figura 3: Reconstituição colorizada do relevo do Jardim com aqueduto. https://en.wikipedia.org/wiki/Paradise\#cite_note-2

No jardim real, da esquerda para a direita, é possível avistar as mãos de uma musicista com tambor e uma harpista entre as coníferas (Figura 1). Nos galhos das árvores observa-se vários pássaros e mesmo um gafanhoto, no canto superior esquerdo. Vê-se servas que usam longas túnicas, faixas na cabeça, joias e estão com os pés calçados. Duas delas portam bandejas 
com alimentos e outras carregam abanadores e toalhas de mão, e todas estão caminhando na direção onde o rei e a rainha se encontram.

Como figura central da cena vê-se o rei assírio Assurbanipal, reclinado em uma poltrona alongada, e diante dele está a rainha assíria Aššur-šarrat entronada. É importante salientar que esse programa iconográfico é sem precedentes na arte mesopotâmica e, segundo Nylander (1999, p. 82), retomaria temas presentes em selos-cilindros elamitas. $\mathrm{O}$ rei veste uma túnica adornada de símbolos e está coberto por uma capa um pouco abaixo da cintura, tem seu braço direito levantado e na mão um cálice que leva na altura da boca, seu outro braço está encostado sobre o móvel e em sua mão esquerda segura uma flor de lótus, que é um símbolo da realeza.

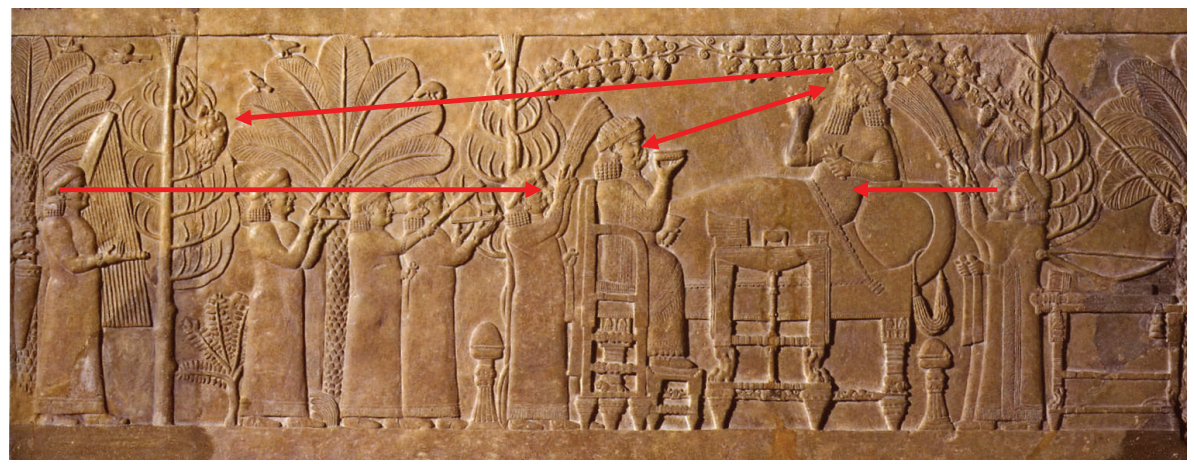

Figura 4: O Banquete sob a Videira.

Alabastro. Iraque, Kouyunjik (Nínive) - Museu Britânico, Londres.

Altura: 1,34 m Largura: 1,53 m.

Reinado de Assurbanipal (668-631 AEC).

(C) The Trustees of the British Museum

https://www.britishmuseum.org/collection/image/237000001

A composição, que é um fragmento parcial de um conjunto ${ }^{2}$ maior, revela que os dois personagens principais que estão em um nível superior aos demais e em escala maior (Figura 4). Mas entre eles as diferenças persistem, pois Assurbanipal, apesar de se situar em um plano intermediário, está em um nível bem mais elevado que a rainha, que, por sua vez, encontra-se no primeiro plano e o olha de baixo. Podemos acompanhar o desenrolar da ação através da condução dos olhares dos personagens. As servas e a rainha direcionam seus olhares para o rei e ele, por sua vez, olha para a cabeça decapitada de Teumman, o soberano do Elão. Assurbanipal e Aššur-šarrat

\footnotetext{
2 Do conjunto dos relevos sobreviveram apenas os desenhos realizados e publicados pelos arqueólogos que o descobriram. Acredita-se as peças em pedra tenham perecido no naufrágio ocorrido no rio Tigre quando de seu transporte à Londres, ainda no século XIX (LARSEN, 2001, p. 328).
} 
estão enquadrados por dois pinheiros, pelos dois queimadores de perfumes no solo e pela videira, destacando-os do cenário (POZZER, 2011, p. 12).

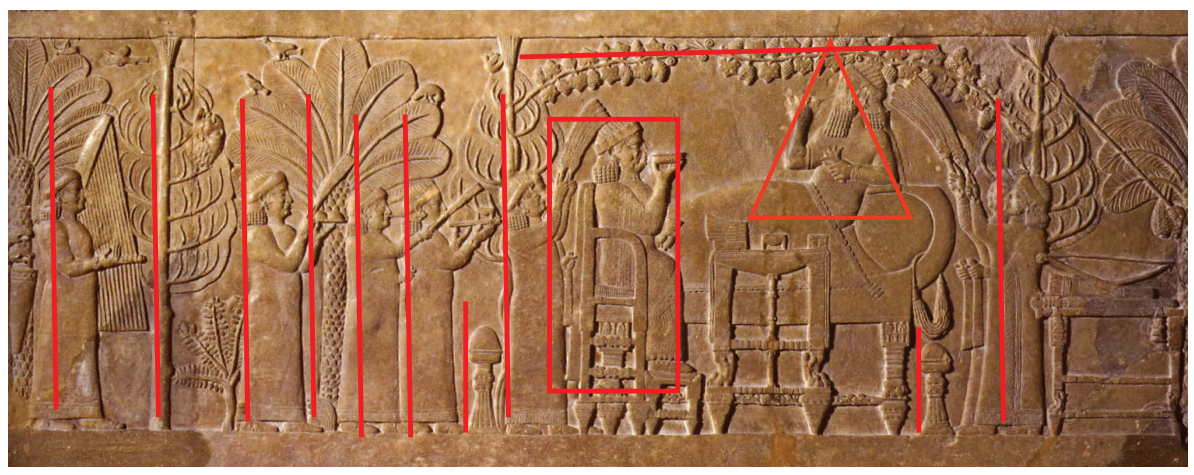

Figura 5: O Banquete sob a Videira.

Alabastro. Iraque, Kouyunjik (Nínive) - Museu Britânico, Londres.

Altura: 1,34 m Largura: 1,53 m.

Reinado de Assurbanipal (668-631 AEC).

(C) The Trustees of the British Museum

https://www.britishmuseum.org/collection/image/237000001

A repetição das figuras femininas, que formam uma verdadeira procissão de serviçais, colabora para infundir um ritmo à composição. Assim, observamos muitos elementos verticais, um retângulo e um triângulo que também contribuíram para evidenciar a figura do casal real (Figura 5). Seguindo a norma da arte mesopotâmica, as figuras humanas apresentam forte lateralidade. As aves nos topos das árvores imprimem certa leveza e movimento à cena, criando uma ilusão de burburinho dos pássaros (Figura 6).

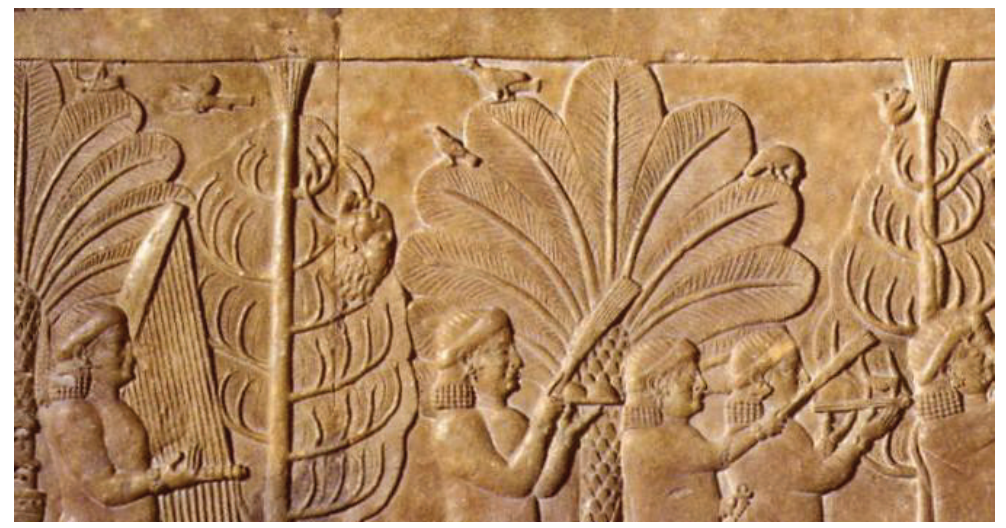

Figura 6: O Banquete sob a Videira (detalhe).

Alabastro. Iraque, Kouyunjik (Nínive) - Museu Britânico, Londres.

(C) The Trustees of the British Museum

https://www.britishmuseum.org/collection/image/237000001 
O rei possui um longa e espessa barba e porta uma coroa decorada com círculos concêntricos enquanto seus cabelos cacheados caem na altura dos ombros. Esta representação do gênero masculino enfatiza os aspectos de maturidade e de vigor sexual do rei. Ele ainda usa brincos e braceletes nos punhos. Sua vestimenta é ornada com formas estreladas, semelhante a uma das representações do deus sol, Šamaš (BLACK; GREEN, 1998).

A rainha Aššur-šarrat porta um vestido que se termina em franjas, ricamente bordado com motivos de pequenos círculos. Ela usa brincos, braceletes e uma coroa em forma de muralha, decorada de torres e ameias, sobre os cabelos ondulados que caem até os ombros. Seus pés estão calçados e repousam sobre um tamborete. Tanto o rei como a rainha não tocam os pés no chão, indicando sua condição social de superioridade. Com a mão direita a rainha leva uma taça à boca, enquanto segura um ramalhete de flores na mão esquerda. As vestimentas e os adereços do casal real são um índice de sua condição social extremamente elevada e colaboram na identificação dos personagens.

Os móveis representados no relevo são altamente sofisticados, decorados com formas de leões ${ }^{3}$ e placas de marfim esculpidas com retratos femininos. Os pés dos móveis são cônicos e ornamentados com volutas florais. A cadeira na qual o rei está reclinado e apoiado em uma grande almofada, tem espaldar arredondado, onde está pendurado um peitoral egípcio, em alusão à conquista do Egito em 667 e 663 AEC. Já a rainha está em um trono esculpido de grande beleza (BENOIT, 2011, p. 403; READE, 2006, p. 88).

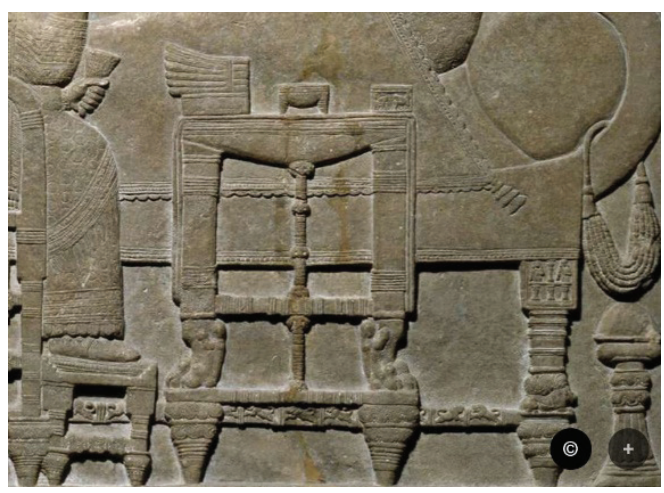

Figura 7: O Banquete sob a Videira (detalhe).

Alabastro. Iraque, Kouyunjik (Nínive) - Museu Britânico, Londres.

Reinado de Assurbanipal (668-631 AEC).

(C) The Trustees of the British Museum

https://www.britishmuseum.org/collection/image/237000001

3 O leão é um animal que simboliza a realeza, a força. 
Diante dos dois convivas vê-se uma mesa recoberta por uma toalha, cujos pés se terminam na forma de patas de leão (Figura 7). Sobre a mesa há uma pilha de guardanapos, um vaso trípode e uma pequena caixa decorada com a figura de dois lamassu. ${ }^{4}$ No canto direito do relevo há uma pequena mesa onde estão depositadas armas de Assurbanipal: o arco, a aljava e a espada embainhada, sugerido um momento de descanso e relaxamento, longe do campo de batalha.

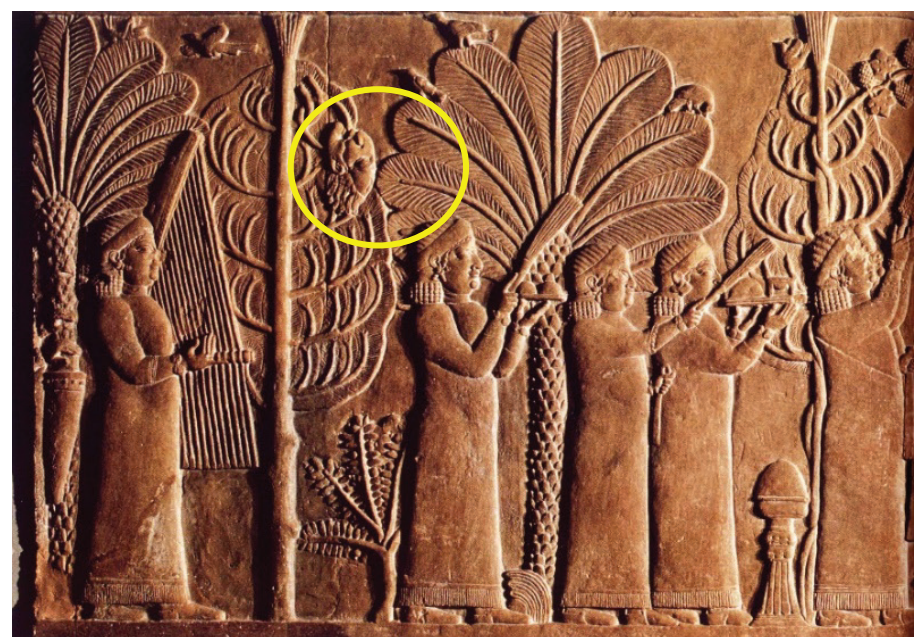

Figura 8: O Banquete sob a Videira (detalhe).

Alabastro. Iraque, Kouyunjik (Nínive) - Museu Britânico, Londres.

Reinado de Assurbanipal (668-631 AEC).

(C) The Trustees of the British Museum

https://www.britishmuseum.org/collection/image/237000001

Mas o elemento mais intrigante da cena é a cabeça de Teumman, o rei do Elão, pendurada em uma árvore (Figura 8). Tanto os anais históricos como o conjunto de relevos localizados nas paredes da sala XXXIII do palácio sudoeste de Senaqueribe relatam que Teumman, que estava em guerra com a Assíria, foi decapitado no meio da batalha de Til-Tuba, em 653 AEC, e sua cabeça foi carregada em um carro de guerra triunfal para a cidade de Arbela no norte da Assíria. Em seguida, ela foi enviada para o palácio em Nínive para compor a ornamentação do banquete comemorativo da vitória assíria. Podemos compreender, portanto, este relevo como um banquete comemorativo de uma batalha que finalizou com a captura e morte do rei

\footnotetext{
4 Os mesopotâmicos acreditavam que esta divindade antropozoomorfa possuía um poder aprotropaico. Estes touros androcéfalos alados, portando a tiara à cornos - atributo da divindade -, eram comumente representados na arquitetura monumental (BLACK; GEORGE; POSTGATE, 2000).
} 
elamita, onde a cabeça era a parte do corpo que atuava como símbolo da evidência da vitória em todo o tempo da narrativa, por ser a parte do corpo que confere identidade à pessoa (CURTIS; READE, 1995, p. 74; WATANABE, 2008, p. 325).

\section{Intervenção iconoclasta}

Devemos observar ainda que parte do relevo foi danificada, o rosto e as mãos do rei e de sua consorte foram martelados. Trata-se de uma ação iconoclasta levada a cabo cerca de quarenta anos depois de sua construção. Acredita-se que ela teria sido empreendida pelos elamitas (os inimigos vencidos na narrativa do relevo) quando a coalizão composta pelos exércitos meda, elamita e babilônico conquistaram a cidade de Nínive em 612 AEC, e levaram ao fim o império neoassírio (ALVAREZ-MON, 2009, p. 134).

A mutilação dos corpos era uma prática atestada na Mesopotâmia e no Egito antigos, tanto na iconografia como na produção textual. A identidade do inimigo morto e do grupo social ao qual ele pertence é colocado em evidência (MINUNNO, 2008, p. 249). Dentre as mutilações possíveis, a decapitação é a preferida, pois “a cabeça é a expressão da personalidade”, única e individual e quando ela é exposta, ninguém pode duvidar de sua morte. O corte das mãos é outro tipo de mutilação bastante utilizado sobretudo no Egito. As mãos também são uma marca da personalidade e cortá-las é um ato simbólico de grande força. A mutilação torna-se, assim, um instrumento de propaganda política. A decapitação dos inimigos era um elemento indispensável na guerra assíria. Após a batalha elas eram mostradas como troféus e eram testemunhas do prestígio e da qualidade do exército vitorioso. O acúmulo de cabeças era um meio de mostrar o poder militar e raras foram as vezes que uma cabeça foi nomeada. No período neoassírio, a conexão simbólica entre a cabeça como um troféu humano e a imagem de poder foram mais evidentes no reinado de Assurbanipal (BONATZ, 2005, p. 96).

Para compreendermos esta iconoclastia é preciso refletir sobre a natureza da imagem na arte antiga oriental. Devemos considerar que a arte no antigo Oriente Próximo é múltipla e diversa, como os povos que ali habitaram. Diferentes períodos históricos e regiões apresentaram, cada um a seu modo, características e desenvolvimento próprios, condicionados pelo meio ambiente, pelas matérias-primas e pelas influências externas, devidas, especialmente, ao comércio de longa distância e às guerras de conquista. Geralmente, os sistemas de representação não eram naturalistas, mas sim idealizados segundo convenções estilísticas com atributos que conferiam 
sentidos específicos e transmitiam mensagens particulares ao observador (BORDREUIL; BRIQUEL-CHATONNET; MICHEL, 2008, p. 42).

E a ideia da representação visual na Mesopotâmia era uma questão fundamental para a história da arte do antigo Oriente Próximo. Eles acreditavam no poder dos significantes e seu status como parte integrante do real. E esse ponto tem estreita relação com a palavra escrita, já que a escrita cuneiforme é definida como simbólica porque o significante (suporte material) é interpretado como capaz de carregar um significado direto (imagem mental). Cada signo, por ter um valor pictográfico e fonético, tem o potencial de evocar outros referentes (objetos) que ele contém (BAHRANI, 2008).

\section{Conclusão}

$\mathrm{Na}$ antiga Mesopotâmia, a imagem não era uma réplica natural, mas sim um código acordado, sujeito a um processo de mediação cultural, uma representação idealizada da realidade. Portanto, a noção de mimesis, de representação como um meio de imitar as coisas reais no mundo, não é suficiente para entender a arte da antiguidade oriental. Partimos da ideia de que a imagem não era considerada semelhante a uma realidade original apresentada em outro lugar (um significado para a palavra representação), e sim a realidade em si. Portanto a mutilação da imagem do rosto e das mãos de Assurbanipal e Aššur-šarrat deve ser entendida como uma tentativa de apagamento da memória deste evento histórico, com a destruição da gestualidade de comemoração e, também, o desejo expresso de levar estes personagens ao esquecimento da história, um castigo terrível para os mesopotâmicos considerado pior do que a morte.

O mito sumério intitulado "Enki, ordenador do mundo" enumera os principais atributos da civilização e entre eles está a arte da guerra e também a da realização de banquetes (BOTTÉRO; KRAMER, 1993). Assim, o relevo aqui analisado comporta estes dois importantes elementos do imaginário mesopotâmico. Podemos compreender estas narrativas artístico-históricas como propaganda política, social, econômica, religiosa, com uma forte carga ideológica, que tinha como objetivo legitimar o poder dos governantes perante seus súditos. Mas, também, poderiam ser objeto de admiração da própria realeza, em uma tentativa de perpetuação de sua imagem e, assim, de seu poder (MARCUS, 2000).

Estes relevos monumentais foram expostos nas paredes internas dos palácios e, portanto, sua circulação era restrita aos convidados do rei e às delegações diplomáticas estrangeiras. Os reis assírios construíram palácios 
para servir de núcleo administrativo, mas também como instrumento de propaganda, decorado de modo a impor ao visitante a impressão da esmagadora potência assíria. Esta decoração fazia, essencialmente, a exaltação da pessoa do rei e da evocação de seus altos feitos para seus contemporâneos e para a história.

As imagens, enquanto um poderoso veículo de comunicação, apresentavam uma narrativa histórica mitologizada, mas ao mesmo tempo eram capazes de evocar a realidade e assim preservar a memória histórica da realeza assíria.

\section{Referências bibliográficas}

ALVAREZ-MON, J. Ashurbanipal's feast: a view from Elam. Iranica Antiqua, v. XLIV, p. 131-180, 2009. doi: 10.2143/IA.44.0.2034378.

BAHRANI, Z. Rituals of war: the body and violence in Mesopotamia. New York: Zone Books, 2008.

BARNETT, R. D. Sculptures from the north palace of Ashurbanipal at Nineveh (668-627 B.C.E.). London: The British Museum Publications, 1976.

BENOIT, A. Les civilisations du Proche-Orient ancien. Paris: École du Louvre, 2011.

BLACK, J.; GEORGE, A.; POSTGATE, N. A concise dictionary of akkadian. Wiesbaden: Harrassowitz Verlag, 2000.

BLACK, J.; GREEN, A. Gods, demons and symbols of ancient Mesopotamia. London: British Museum Press, 1998.

BONATZ, D. Ashurbanipal's headhunt: an anthropological perspective. Iraq, v. 49, n. 1, p. 93-101, 2005.

BORDREUIL, P.; BRIQUEL-CHATONNET, F.; MICHEL, C. Les débuts de l'Histoire. Paris: Éditions de La Martinière, 2008.

BOTTÉRO, J.; KRAMER, S. Lorsque les dieux faisaient l’homme. Paris: Éditions Gallimard, 1993.

BRITISH MUSEUM. < https://www.britishmuseum.org/collection/image/237000001.>2021.

CURTIS, J. E.; READE, J.E. Art and empire: treasures form Assyria in the British Museum. New York: The Metropolitan Museum of Art, 1995.

FRANKFORT, H. The art and architecture of the Ancient Orient. New Haven; London: Yale Univesity Press, 1996.

GLASSNER, J.-J. Chroniques mésopotamiennes. Paris: Les Belles Lettres, 1993.

JARDINS D'ORIENT. De l'Alhambra au Taj Mahal. Paris; Gand: Institut du Monde Arabe; Snoeck, 2016.

LARSEN, M. T. La conquête de l'Assyrie 1840-1860. Paris: Hachette, 2001.

MARCUS, M. Art and ideology in ancient Western Asia. In: SASSON, J. M. (ed.). Civilization s of the ancient Near East. Peabody: Hendrickson Publishers, 2000, p. 2487-2505. 
MINUNNO, G. La mutilation du corps de l'ennemi. In: ABRAHAMI, Ph.; BATTINI, L. Les armées du Proche-Orient (III-Ier mill. av. J.-C.). Oxford: British Archaelogical Reports, 2008, p. 247-256.

MOSCATI. S. Como reconhecer a arte mesopotâmica. São Paulo: Martins Fontes, 1985.

NYLANDER, C. Breaking the cup of the kingship an elamite coup in Nineveh? Iranica, v. XXXIV, p. 71-83, 1999.

PANOFSKY, E. Significados nas artes visuais. São Paulo: Perspectiva, 2007.

PARADISE. Wikipedia. < https://en.wikipedia.org/w/index.php?title=Paradise\&old

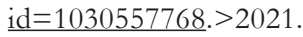

POZZER, K. M. P. A Comemoração da vitória: o banquete triunfal assírio. Anais do XXVI Simpósio Nacional de História - ANPUH. São Paulo, julho 2011, p. 1-14.

READE, J. Assyrian sculpture. London: The British Museum Press, 2006.

RUSSELL, J. M. Sennacherib's palace without rival revisited: excavations at Nineveh and the British Museum Archives. In: PARPOLA, S.; WHITING, R. Assyria 1995. Helsinki: The Neo-Assyrian Text Corpus Project, 1997.

WATANABE, C. The classification of methods of pictorial narrative in Assurbanipal's reliefs. Studies in Ancient Oriental Civilization, n. 62, p. 321-331, 2008. 